\title{
The Intervention Program "The Voice of the Other"
}

\author{
Zahava barkani* \\ Department of Education, Hakibbuzim College, Tel-Aviv, Israel \\ *Corresponding author: zbarkani@gmail.com
}

Received October 04, 2014; Revised December 03, 2014; Accepted December 24, 2014

\begin{abstract}
This study examined the impact of the intervention program "The Voice of the Other" on student teachers and the process that the students undergo throughout the program. This study also examines the impact of the unique tools that influenced the process.
\end{abstract}

Keywords: the other, teacher training, critical education, experiential learning

Cite This Article: Zahava barkani, “The Intervention Program "The Voice of the Other".” American Journal of Educational Research, vol. 2, no. 12 (2014): 1260-1266. doi: 10.12691/education-2-12-21.

\section{Introduction}

In the spirit of critical pedagogy, the intervention program "The Voice of the Other", focuses on developing the student teacher's awareness and moral and social thinking and formulating the student's political worldview, as well as raising the awareness of the moral defects of a non-equal society, and providing the ability and desire to educate and learn to implement social change.

The Voice of the Other is a journey of learning based on the transition from learning about the "outer world" to learning about and in the "inner world"; from objective judgment to subjective listening, from knowing to unknowing, from answers to questions, from being a passive human being towards the environment to being active; a passage from silence to crying out.

Principles of dialogue and multi-cultural perception are rooted in the critical spirit of the program making the learning process in the program an egalitarian process. The connection between fieldwork learning within social organizations and classroom study will expose Academia to the streets, and connect academic knowledge to reality.

This connection will allow the students to move from being a person watching reality to one of action, changing the current reality by changing consciousness and practical action in the streets.

The program encourages the development of selfcriticism and reflection, understanding cumulative experiences to enable students to continue working to achieve a just society.

At the core of the intervention program is the concept that transformative training is needed to foster teachers with social-political awareness in response to the educational institutions subordination of the laws of the free-market, and to narrow standards of knowledge as part of New-liberal economic fundamentals.

\subsection{Background}

In the last three decades Israeli society underwent comprehensive changes from a solidarity society to an individualistic and alienated society similar to other western cultures. Since the late seventies the State of Israel adopted the Neo - liberal economic fundamentals and institutionalized the process of privatization and decentralization of government and public institutions. These processes have created a social reality of expanding gaps, the erosion of the welfare state and a massive increase in private expenditure required for providing basic social services like health and education [12].

In response to the distress and social needs that developed, a third sector arose. This sector includes many welfare organizations and charities [2,3].

These social processes are deeply affected by the global post-industrial trends that are prevalent in the Western world. These trends include the establishment of a consumer culture that has no desire for social improvement. The philosopher and sociologist Christopher Lasch calls it a "culture of narcissism." He argues that this culture cultivated a generation that is missing its social compass, and is characterized by civil and political indifference [7].

Together with social nihilism that nurtures a culture of conspicuous consumption, the global trends also bring the nation to break with traditional boundaries and create a sectorial identity with ethnic, religious or community emphasis. Some fear that these effects, which were reinforced by the relativism of post-modernistic trends, would preclude any attempt to establish a welfare policy $[4,11]$.

Public education was influenced by these changes. I will mention three forces that contribute to the weakening of the public education system and its fragmentation:

1. Reduction in public education funding, implementation of a business management style, and reference to students and parents as customers.

2. Cultural communities of different ethnicity seeking to expand their educational autonomy in the name of multiculturalism. Due to this trend the state has difficulty establishing a basic curriculum. 
3. Parents from the upper socio-economic class bypass the public school system and establish private education systems [6,9].

The weakening of the public education system intensifies the displacement of the political and ethical dimensions of the educational discourse, and focuses both the teaching and the learning on instrumental goals, subordinating them to measurable narrow standards [10].

Macphail and Kaur [8] argue that the education system adapts to the political mood that is in the air. They state that public education at the beginning of the 20th century under the political trends of the time was characterized by an optimistic vision of democracy, whereas today, the education system is affected by the spirit of neo-liberal politics. This results in subordination of the educational institutions to the laws of the free-market and to narrow standards of knowledge.

Because of the new political economic social realities, I believe that we have to promote teacher education programs in the spirit of critical education, so that the student teachers will be able to understand the context and needs of the society in which they live and can affect it by educating.

\subsection{Aim of the Intervention Program}

The aim of the intervention program "The Voice of the Other" is to be a training program that cultivates educators equipped with vision, a mission and professional selfconfidence - intellectuals who change the world. These are critical educators with broad social knowledge who develop the consciousness of active democratic citizens among their students and provide a meaningful and relevant learning experience.

The program aims to:

- Promote changes in the training of teachers out of the belief that changing society begins with education.

- Extend the student teacher's political consciousness and social awareness [1].

- Create opportunities for the student teachers to meet with the social Other and in a parallel process with his own otherness and later on with the Others in the class [14].

- Assume responsibility for the other as part of basic human responsibility.

- Influence the student to be active educators who hold the hope for positive social changes in society [5].

- To expose students to different voices hidden in the cultural context, the voices of minority groups that have hitherto been denied proper expression in the hegemonic culture [13].

\subsection{Research Questions}

1. What is the process students undergo in the program?

a. Their point of view, their testimony, their process of reflection about the awareness of the other and their own otherness, their critical thinking towards today's reality and their ability to take a stand.

2. Does the program develop awareness of the other?

3. Will the student teachers recognize the connection between the Other in the classroom and the social Other?
4. What in the character of the program (ways of learning) contributes to the student's perception of the above?

5. Does the program develop awareness of the student's own otherness?

6. Does the program develop critical thinking towards today's reality among the students?

7. Does the program develop the characteristics of empathy and tolerance?

8. Does the program develop the concept of "intellectuals changing the world"?

\section{Materials and Methods}

\subsection{Research Design}

This research combines qualitative and quantitative research. Both examine the change in students' attitudes toward the Other and the process that the students undergo throughout the program.

\section{Research Population}

The research population consisted of 50 studentteachers who participated in the program during their Bachelor of Education degree studies at Seminar Hakibbutzim College between 2007-2012. The majority of the program's population were female, $30 \%$ were male. Most were unmarried, under the age of 30 , and after mandatory military service.

\subsubsection{Quantitative research: Examination of attitudes towards the other by questionnaires}

Fifty questionnaires are administered at two points in time to the same students: before participating in the program and at the end of it. The first questionnaire consists of fifteen statements and five categories. The second consists of twenty-one statements and five categories.

The questionnaires examine and test a number of quantitative parameters and objective changes in patterns of thinking and attitudes of the students about the social Other and the Other within them. It also examines their ability to be critical of the phenomena that occur in society, as well as their ability to make a connection between social phenomena and their own responsibility. The questionnaires are $\mathrm{T}$ tested for correlated samples.

In accordance with the program objectives there are two questionnaires:

- The first questionnaire, given to students at the beginning of the program, deals with attitudes towards the Other, willingness to meet with the Other, the connection between education and the topic of "the other ", and the responsibility towards the Other.

- The second questionnaire is for the same students, after graduating from the program. The questionnaire examines the concept of the impact of the program on the students: their identity as a teacher, their personal identity and their attitudes towards the Other, their awareness of the Other, and their satisfaction from the program's unique way of learning and its impact on their attitudes toward the Other. 


\subsubsection{Qualitative Research: Reflective Diary Analysis}

The qualitative research complements the quantitative research by examining different aspects of the same research. The character of the data is such that you cannot quantify them. For example: the process that the students undergo during the program and the program highlights.

The qualitative research occurs at the end of the program - each student creates a Reflective Diary in which he documents the activities undertaken during the program and his own process and his insights from the process. In the qualitative research there are major themes that arise from this Reflective Diary:

Differences in students' attitudes before and after participation in the program.

Awareness and responsibility for the Other and the relationship between the Other and education.

The impact of experiential learning on the development of insights and awareness.

\subsubsection{Research Variables}

\section{Dependent}

1. The weight of experiential learning
2. The weight of the responsibility for the other

3. The weight of the influence the encounter with the other has on student teachers

\section{Independent:}

- The implementation of the program "The Voice of the Other", based on social sciences and education science, as part of the college curriculum for students of education in their first year of studies.

\section{The Results}

\subsection{Quantitative Research Findings and Analysis}

To support the qualitative part of the research a quantitative analysis of the differences was administered through questionnaires given to students before the program and to those same students after graduating from program.

In order to compare between the samples a paired samples t-test was conducted. Table 1 show the averages, the standard deviations and t values for comparing items.

Table 1. The means, standard deviations and $t$ values for comparing items

\begin{tabular}{|c|c|c|c|c|c|}
\hline & \multicolumn{2}{|c|}{ Before } & \multicolumn{2}{|c|}{ After } & \multirow[t]{2}{*}{ t value } \\
\hline & M & SD & M & SD & \\
\hline Responsibility for the Other & 2.98 & 0.62 & 4.28 & 0.671 & $12.053 * * *$ \\
\hline Identification with the Other & 1.80 & 0.881 & 3.18 & 0.825 & $9.146^{* * *}$ \\
\hline The Other in myself & 2.14 & 1.010 & 3.48 & 0.762 & $7.751^{* * *}$ \\
\hline Importance of personal life story & 2.32 & 0.794 & 3.84 & 0.738 & $10.806^{* * *}$ \\
\hline Awareness of the Other & 2.98 & 0.416 & 4.24 & 0.555 & $13.261^{* * *}$ \\
\hline The connection between the Other and education & 2.54 & 0.523 & 4.38 & 0.435 & $17.456 * * *$ \\
\hline
\end{tabular}
$* * * \mathrm{p}<0.001$

As canbe seen in both the table and chart, there are significant differences in students' attitudes before and after participation in the program. T-test showed that the differences are significant.

It was found that after participation in the program students reported greater responsibility for the Other, more identification with the Other, and a higher degree of

inclusion of the Other within the students' personal identity. Students also reported a greater interest in their personal life story and a greater awareness of the Other. Also, after participation in the program students saw a greater degree of connection between education and the Other.

Table 2. The frequencies and percentages of the variables related to satisfaction with the program and its impact

\begin{tabular}{|c|c|c|c|c|c|}
\hline & & $\mathrm{N}$ & $\%$ & $\mathrm{M}$ & SD \\
\hline \multirow{4}{*}{ The significance of personal life stories in the classroom } & Moderately & 1 & 2 & & \\
\hline & Very & 30 & 60 & 4.36 & 0.525 \\
\hline & Extremely & 19 & 38 & & \\
\hline & Moderately & 1 & 2 & & \\
\hline \multirow[t]{3}{*}{ Development of responsibility of the other in the classroom } & Very & 31 & 62 & 4.34 & 0.519 \\
\hline & Extremely & 18 & 36 & & \\
\hline & Moderately & 3 & 6 & & \\
\hline \multirow[t]{2}{*}{ Acquisition of tools in the program for educational activities } & Very & 31 & 62 & 4.26 & 0.565 \\
\hline & Moderately & 1 & 2 & & \\
\hline \multirow[t]{2}{*}{ The influence of the program on the students' professional identities as educators } & Very & 35 & 70 & 4.26 & 0.487 \\
\hline & Extremely & 14 & 28 & & \\
\hline
\end{tabular}

\section{Satisfaction with the Program}

The second measure asked students to report their satisfaction with the program and the extent to which the program has influenced their personal identity and their professional identity as educators. Table 2 describes the distribution of the answers to these questions.

The figure shows that in general participants reported high satisfaction with the program.

Regarding the significance of personal life story in the classroom, $60 \%$ of the students reported a high degree of importance and 38\% reported an extremely high degree of such importance. An additional 2\% reported a moderate effect. None of the students reported little effect or no effect at all.

Regarding the effect of the program on the development of responsibility for the Other in the classroom, $62 \%$ of the students reported a high degree of influence and another 36\% reported an extremely high degree of such influence. An additional 2\% reported a moderate effect. None of the students reported little effect or no effect at all. 
Regarding the acquisition of tools in the program for educational activities, $62 \%$ of the students reported a high degree of impact of the program on making educational tools and 32\% reported an extremely high degree of such influence. 6\% reported a moderate effect. None of the students reported little effect or no effect at all.

Regarding the effect of the program on students' professional identity as educators, $70 \%$ of the students reported a high degree of impact on their professional identity and 28 students reported an extremely high degree of such influence. An additional 2\% reported a moderate effect. None of the students reported little effect or no effect at all.

Table 3. Frequencies and percentages of the variables relating to the contribution of experiential learning to the development of awareness and understanding in the students

\begin{tabular}{|c|c|c|c|c|c|}
\hline & & $\mathrm{N}$ & $\%$ & $\mathrm{M}$ & SD \\
\hline \multirow{3}{*}{ Learning in the streets } & Moderately & 1 & 2 & 4.68 & 0.513 \\
\hline & Very & 14 & 28 & & \\
\hline & Extremely & 35 & 70 & & \\
\hline \multirow{4}{*}{ Films } & Slightly & 2 & 4 & 3.92 & 0.724 \\
\hline & Moderately & 9 & 18 & & \\
\hline & Very & 30 & 60 & & \\
\hline & Extremely & 9 & 18 & & \\
\hline \multirow{4}{*}{ Protest Music } & Slightly & 6 & 12 & 3.48 & 0.814 \\
\hline & Moderately & 18 & 36 & & \\
\hline & Very & 22 & 44 & & \\
\hline & Extremely & 4 & 8 & & \\
\hline \multirow{2}{*}{ Meetings with the Other } & Very & 22 & 44 & 4.56 & 0.501 \\
\hline & Extremely & 28 & 56 & & \\
\hline
\end{tabular}

The table shows that in general participants reported a very high impact of experiential learning for developing insights and awareness. 28\% of the students reported a high degree of impact of experiential learning and 70\% reported an extremely high degree of such influence. An additional $2 \%$ reported a moderate effect. None of the students reported little effect or no effect at all.

Regarding the contribution of films as part of the experiential learning program, $60 \%$ of the students reported a high level of contribution and 18\% reported an extremely high degree of this contribution. $18 \%$ reported a moderate contribution and $4 \%$ of the students reported little or no contribution.

About the contribution of protest music as part of experiential learning, $44 \%$ of the students reported a high contribution and 8\% reported an extremely high degree of this contribution. An additional 36\% reported a moderate contribution and $4 \%$ of the students reported little or no contribution at all.

About the contribution of meetings with the Other as part of the experiential learning, $44 \%$ of the students reported a high level of contribution and 56\% reported an extremely high degree of contribution regarding an encounter with the other as part of the experiential learning experience.

As shown in the findings, there are significant differences in students' attitudes before and after participation in the program.

It was found that after participation in the program students reported greater awareness and greater responsibility for the Other, as well as seeing more clearly the relationship between the Other and education.
The study also found that in general participants reported very high impact of experiential learning on the development of insights and awareness.

The results show that learning in the streets and meetings with the Other has the highest contribution as part of experiential learning, and that film and protest music made high contributions.

\subsection{The Qualitative Findings and Analysis the of Reflective Diary}

3.2.1. The Students Describe in their Writing the Process they Underwent from the Decision to Learn in the Program until the End of the Program

The students write about the expectations they had from the program: "The program attracted me at first because of the title but I was hooked when I realized it was my chance to cross the lines, to see, to feel the Other Tel Aviv as a microcosm of Israel".

The students describe the complex feelings they had at the beginning of the program: "At the beginning of the program I came out of every meeting with an understanding and an understanding accompanied by fear. It felt like a process of maturing. I wanted to break out - to see, but I still wanted to stay in a familiar and congenial place".

The students write about the social issues they were exposed to that shook them: "During the program, I was exposed to things my parents tried to protect me from all my life, such as prostitution, refugees, drugs and drug addicts. This exposure hit a nerve which left me hurt, scared, angry, confused, and mostly helpless".

The students discover their racism: "We are all racists. I'm racist. How easy is it to speak out against racism and know in my head occur racist thoughts. I judge people by the color of their skin, by appearance. That I unconsciously create racism against people who are unfamiliar, who scare me, is awful."

The students describe the moment of change at the point of no return: "Slowly, the more we got into the streets, we met people from the margins of society, saw movies that show more and more stories; we talked about things in the classroom. All of the sudden I realized that I need to know, I need to be exposed".

The students write about their change of attitudes: "I have no doubt that the program has changed my attitude: I learned many new things, and my sense of apathy towards the situation changed to an awakening and a desire to change and influence".

\subsubsection{The Students Write about Experiential Learning}

The students describe going out into the streets, out of the closed classrooms and into a familiar but strange and scary world: "The tour made me think about my place, the comfort that I have to have as a privileged man in society, as part of the majority. It made me think about my indifference towards minorities in society, those whose voices are not heard, and how I ignore the fact that the state harms them by controlling them as a minority".

The students write about the stereotypes and prejudices they felt about the "Other" and his or her story: "I felt I was looking at him critically, that I do not believe him, I do not accept his views. It took me a while 
till the judgment calmed down and suddenly I could for a moment listen to him, hear him talk about his difficult".

The students write about their feelings of guilt: "I looked at him and felt guilty of his life story. Maybe guilt that I did not know that there are people that this is their story, perhaps guilt that I cooperate through ignorance with government policy".

The students write about their identification with the storyteller: "Something in the stories I've been exposed to was very human and touched me deep inside. This Connection was very painful. I thought I was out of the story and I realized I was one story in a sea of human stories".

The students write about their insights from the meeting with the Other: "I mostly learned to watch closely/observe. Take the story, and examine it. To listen for a minute. Look at all sides. Be for a second in its complexity, before jumping to conclusions, before taking positions, before doing something, and understanding the complexity is everywhere." Especially under our noses".

The students write about the impact of experiential learning tools such as a film, a work of art, and protest music on the students' learning: Movies-"This film gave me the opportunity to see both sides of the coin. I did not feel a manipulation being made on the film viewer, but on the contrary, I felt the need of the artist to bring the real, empathetic and painful place". Art-"We created masks in class. Working with art materials was exciting for me. Creating myself in art material is like looking in the mirror". Protest music - "The music screams the social shout. The Sounds have something deep in them. Something that forces us to listen".

The students write about their responses to experiential learning: "When I see, hear, smell - I cannot say it does not exist. When a person sits in front of me and tells me about his difficulty I cannot say - there is no problem. It confronts me with reality and especially with my perceptions towards that person".

\section{Conclusions}

\subsection{The Conclusions of the Research}

The intervention program "The Voice of the Other" is an educational academic program that exposes the student-teachers to the Other and uses that encounter, through which occur educational, group and personal processes.

The encounter with the other is both the essence of the program and the method that is the basis of the program. The future educators in the program experience the encounter with the other and create a personal affinity between themselves and the other.

The program is aimed towards a varied group of students. Each student in the program experiences different processes because each student comes with his or her own knowledge of the world, as well as his or her unique life story, age and marital status.

The encounter with the other generally creates internal and external conflict because usually the Other is not marginalized by chance. With the encounter with the other comes the things we run away from: the strange ways of thinking, the alternative living, the people we might have been and the people we do not want to be.

By exposing the student teachers to the other by the intervention program "The Voice of the Other", they were exposed to their own otherness, their own inner dialog and their own narratives, thus they were exposed to themselves. They could see themselves as the other, and they could see the other as being like them. The student teachers developed awareness and moral and social thinking and a desire to educate and learn to implement social change

By exposing the student teachers to the Other and their own otherness it was my way to show them that each one of us, and of course one of their future pupils in the classroom, is the other, thus creating a space for dialogue with the other in their future classroom.

\subsection{General Conclusions}

\subsubsection{Exposure to the Other}

A student teacher who has not been exposed to the Other cannot be considered a "completed" educator. Exposure to the Other in the process of teacher training fulfills the professional identity of the student teacher by expanding the concept of education to include the social aspect, and simultaneously allowing confrontation with the student's own otherness of which he is usually unaware. This exposure gradually causes the student to feel that he is responsible for the other and a dialogue ensues in which the other is a priority. Dealing with the issue of the other allows a deep understanding of the relationship between people. This issue has several levels: the initial level is the otherness of the student teacher himself, the second level is the social other. By dealing with these two levels a third evolves, one that sharpens the student teachers ability to recognize and help the other in the classroom.

\subsubsection{Am I a Racist?}

The greatest discovery for the students in the program The Voice of the Other is the discovery that they too harbor racist thoughts. Through the program they develop the ability to point at themselves and say "I was being racist against...." An understanding develops that racism exists in everyone, feeding fears of the unknown. As long as a racist position is held towards others, harmonious living will not be possible. As the Other becomes 'familiar' by the educational processes, racist thoughts blur, and sometimes even disappear.

\subsubsection{The Processes of Becoming Aware}

The ethos of a "liberating educator" can arise only if the student himself has experienced a liberating process, one in which he discovers that he can, if he wishes, free himself from the shackles of culture.

Developing processes of awareness is a process that never ends since society is always pushing the norms. It is important that educators continue the learning and practice of this important issue while working in education.

\subsubsection{Being a Critical Thinker}

Critical thinking cannot be taught through logic as logic dictates safety, security and calm and critical thinking 
threatens to stir the safety. In order to teach student teachers to be critical thinkers it must come from the students themselves experiencing dissatisfaction with the way things are. This can be achieved through experiential learning. This way they themselves discover critical thinking, rather than being 'told' to be critical. The development of critical thinking happens through constant dialogue about stances and points of view, and through constantly testing the facts. So that critical thinking can flourish the dialogue and the fact testing must be norms in the educational process.

\subsubsection{Being before Doing}

When students encounter social problems the desire to do something about it immediately arises. In order to feel that they have some control over the bad situation they want to solve the problem. But as educators, it is very important to pause and observe, and to investigate, because immediate action halts the process of awareness as well as gives satisfaction that leads to calm. In order to guide the student teachers to awareness they must experience helplessness, doubt and questioning and as such must not be allowed immediate action. The time for action is at the end of the process when the students have listened to their inner voices, accepted them and then the social situation will be clearer. Then the students can make decisions about how and where to act, as well as make clear goals for themselves.

\subsubsection{Breathing Life into Learning}

It is very important to create authentic environments for student teachers. Instead of reading about the social issues, take the students to meet people who are experiencing that same issue. Allow the students to feel a connection with the victim of the social injustice. In a situation like that they are not passive readers in the classroom, but witnesses to the difficulty. Learning of social issues on the street enlists the student's inner motivations for action, thereby beginning the process of awareness, as well as sparks the student's desire to learn more - this is the time for reading, when the student is already involved. It is very important that the students experience diverse, experiential learning, and see it as the worthy method of learning which may echo in their own classrooms in the future.

\subsubsection{Being a Teacher of Teachers}

A teacher of teachers cannot be an ordinary teacher. They must have all the abilities and characteristics of any teacher, but at a higher intensity, this is in order to mold a new kind of educator since it's through education that change can be brought about. The teacher of teachers must be open, trustworthy, someone who is and will always be a learner himself, and passionate about education. In addition, he must be able to change as facts and situations change, in order to lead his student teachers through their own inner changes and thus able to be flexible themselves. He must be a critical thinker himself, and his students, seeing this will too learn to be critical thinkers. Being a teacher of teachers isn't a job, it's a mission.

\subsubsection{Empathy and Solidarity are not Characteristics}

Research question number 7 asks if the program develops the characteristics of empathy and tolerance. I discovered due to this research that empathy and solidarity are not characteristics they are abilities. When I began this research I wanted to see if my program can influence the students to be empathic human beings. I discovered during the research that this is impossible. I discovered that empathy, like solidarity, are not characteristics but rather reactions to a situation in which the students experience moments of empathy or solidarity. These moments of being in the other's shoes and seeing through the other's eyes don't happen by themselves, but when they do happen they are very intense. To say that the student has become empathic is impossible because it is an absolute statement. Human beings are constantly tested by situations that call for humanitarian behavior, the behavior is not a given. I believe that the emotional involvement of teachers and constant work on improving their student's emotional strength will help them pass these tests and lead to humanitarian behavior.

\subsubsection{The contribution of the Research}

Research of The Voice of the Other made contributions to the field of education, teacher training programs and to research methodology.

\section{Contributions to Teacher Training Programs}

1. My research shows how insights in critical thinking can be used in teacher training.

2. My research shows how teaching two disciplines (with common issues) at the same time enrich one another. Studying the insights of both sociology and education at the same time contributes to the future teacher's awareness and critical thinking.

3. My research shows that integrating theory with social action increases moments of empathy within student teachers by involving them personally.

4. My research shows that exposing student teachers to the other and listening to his life story begins an inner dialog within the students that later on develops into a dialogue in the classroom. This research has shown that by being heard the student teachers understood that to be heard is to exist. This experience creates a significant tool that will allow their own students to continue the dialogue.

5. My research shows the deep influence of combining the three aspects: knowledge, inner processes and pedagogy together.

6. My research breaks the belief that the teaching of teacher training programs must be in the classroom, and recommends alternative ways.

7. My research shows the ability of the student to make a change in his or her personal identity while changing his or her professional identity.

\section{Contributions to the Field of Education}

1. My research shows that The Voice of the Other acts as a program that successfully deals with the problems of racism, violence and social alienation in a school environment.

2. A basic belief I hold is that through education changes in society can happen. As such, my research offers an educational model for the classroom to 
prepare the next generation to bring about the change of an equal society.

3. My research shows that teaching student teachers in the streets is a successful and effective teaching tool because it builds a bridge between Academia and life.

\section{Contributions to Research Methodology}

1. By researching my own students, only those students who have participated in The Voice of the Other, I found that it is possible to use this as an advantage since I am aware of all the nuances of the delicate processes that they underwent.

2. The research follows and examines two parallel processes (personal and professional) that the students underwent during the program showing that it is an effective method of research because it exposes that in fact these two levels exist within education research and should be addressed.

3. This research used the mixed methodology of both quantitative and qualitative research. The quantitative - researching students' stances before and after the program, while the qualitative reviewed the innerpersonal and professional processes the students experienced. By using a mixed methodology I was able to show that the two complete each other.

\subsubsection{Limitations}

The limitations of the research to take into consideration are as follows:

- This research examines the impact and the process the students underwent during "The Voice of the Other," a program I developed, taught and researched. As the researcher of the program's effects as well as its creator there is a chance of bias.

- Qualitative research relies on the Reflective Diary Analysis, where students wrote during the course of the program. The students were aware from the beginning of the program that I will read the diary and this could have affected their writing.

\subsubsection{Recommendations for Further Research}

- In order to fully understand the impact of the program The Voice of the Other on student teachers, I recommend further research of former students who are currently teaching in the classroom, to examine the impact of the program on their function as teachers.

- I would like to recommend further investigation of "learning in the streets" as the focus of research, to try to examine the impact of such learning in education.

\section{References}

[1] Bashir-Ali, K. (2011) Socio-cultural theory and its place in the development of the teacher education program at the Higher Colleges of Technology, Education, Business and Society. Contemporary Middle Eastern Issues. 4 (2) p. 106-113. Somalia: Emerald Group Publishing

[2] Gidron, B. (1997) The evolution of Israel's third sector: The role of predominant ideology, Voluntas: International Journal of Voluntary and Nonprofit Organizations. 8 (1) p. 11-38.

[3] Gidron, B., Bar, M. and Katz, H. (2004) The Third Sector in Israel: Between Civil Society and the Welfare State. New York: Kluwer Academic/Plenum Publishers.

[4] Gitlin, T. (1996) The Twilight of Common Dreams: Why America is Wracked by Culture Wars. New York: Metropolitan Books/ Henry, Holt.

[5] Green. G and Ballard, G. H. (2011) No substitute for experience: Transforming teacher preparation with experiential and adult learning practices. SRATE journal. Winter 2010-2011, 20 (1), p. 12. Texarkana, Texas: A\&M University.

[6] Ichilov, O. (2009) The Retreat from Public Education: Global and Israeli Perspectives. Dordrecht, the Netherlands: Springer.

[7] Lasch, C. (1991) The Culture of Narcissism: American Life in an Age of Diminishing Expectations. New York: W.W. Norton and Company.

[8] MacPhail, J. C. and Kaur, B. (2007) In search of a participatory democratic vision in teacher education, in Freeman-Moir, J. and Scott, A. (eds.) Shaping the Future: Critical Essays on Teacher Education, p. 235-256. Rotterdam: Sense.

[9] Michaeli, N. (2008) Unseen hand and an outstretched arm: Pedagogical aspects of privatization of education. Turning. 58. p. 27-32.

[10] Nichols, S. L. and Berliner, D.C. (2007) Collateral Damage: How High Stakes Testing Corrupts America's Schools. Cambridge: Harvard Education Press.

[11] Rorty, R. (1998) Achieving Our Country: Leftist Thought in Twentieth Century America. Cambridge: Harvard University Press.

[12] Shafir, G. and Peled, Y. (2000) The New Israel: Peacemaking and Liberation. Colorado: West View Press.

[13] Smith, T. and Knapp, C. (eds.) (2011) Sourcebook of Experiential Education. New York: Routledge.

[14] Yuval-Davis, N. (2010) Theorizing identity: Beyond the us and them dichotomy. Patterns of Prejudice. 44 (3) Routledge. p. 261280. 